\title{
O USO DO ARTEFATO TECNOLÓGICO SKYPE COMO INSTRUMENTO DE ENSINO E APRENDIZAGEM NAS AULAS INTERDISCIPLINARES DO EMITEC/BA
}

\author{
SALVADOR/BA MAIO/2018
}

\author{
Letícia Machado dos Santos - SEC/BA - Imachado.ead@gmail.com \\ Maria de Fátima Ferreira Lopes Fonseca - SEC/BA - falopes2007@yahoo.com.br \\ Marcia Maria Vieira da Silva - SEC/BA - marcia.silva4@educacao.ba.gov.br \\ SILVANA DE OLIVEIRA Guimarães - SEC/BA - silvanaoguimaraes53@gmail.com
}

Tipo: Relato de Experiência Inovadora (EI)

Categoria: Métodos e Tecnologias

Setor Educacional: EDUCAÇÃO MÉDIA E TECNOLÓGICA

\begin{abstract}
RESUMO
Este artigo propõe a apresentação de um relato de experiência exitosa, fazendo uso do Skype nas aulas interdisciplinares do Ensino Médio com Intermediação Tecnológica (EMITec). Assim, o presente trabalho objetiva promover uma reflexão sobre o potencial e o uso pedagógico de artefatos tecnológicos, mais especificamente o Skype, em aulas interdisciplinares do EMITec. A experiência foi desenvolvida entre os professores da área do conhecimento Linguagem, Códigos e suas Tecnologias, fazendo uso do tema transversal Empreendedorismo e Economia Solidária. O uso do artefato tecnológico Skype, na educação, possibilitou o diálogo entre convidado externo, alunos e professores dos componentes curriculares Arte e Língua Portuguesa, promovendo um processo de interatividade, via chat, em diferentes localidades do Estado da Bahia, através da intermediação tecnológica. Esse processo interativo proporcionou a construção de conhecimentos de forma colaborativa e significativa junto aos estudantes da $3^{a}$ série do ensino médio do EMITec. A metodologia utilizada para a construção desse trabalho foi a pesquisa bibliográfica, e de campo junto ao Programa Ensino Médio com Intermediação Tecnológica, tendo como aporte teórico Bonilla (2010), Castells (2012), e Santiago (2016) entre outros.
\end{abstract}

Palavras-chave: Aprendizagem Colaborativa. Artefatos tecnológicos. Ensino Médio com Intermediação Tecnológica. Interdisciplinaridade. Skype. 


\section{INTRODUÇÃO}

Vive-se em tempos de grandes incertezas e desafios, na era da sociedade em rede, em que os avanços tecnológicos impõem a todo instante demandas e posturas sociais que necessitam de uma formação continuada consistente voltada para essa sociedade sedenta de saberes, e em constantes transformações. Transformações que exigem dos atores envolvidos no processo, neste caso educacional, novas posturas com uso de metodologias ativas, que possam promover atitudes reflexivas e críticas e que dialoguem com o contexto em que se inserem.

Para acompanhar essas transformações, surge então a lógica do funcionamento em rede, cujo símbolo é a Internet, que se tornou aplicável a vários tipos de atividades, de contextos diferentes e a todos os locais que possam ser conectados eletronicamente (CASTELLS, 2012).

Necessário se faz compreender que o potencial pedagógico que as ferramentas tecnológicas possibilitam ao processo de ensino e aprendizagem vai além da inclusão digital. Apropriar-se das tecnologias no ambiente educacional, possibilita aos atores envolvidos construir, modelar fenômenos em quase todos os campos de conhecimento, além de facilitar o processo de transmissão de informações e favorecer a construção de novos saberes.

Bonilla (2010) considera que promover a inclusão digital é oportunizar que cada sujeito social possa, efetivamente, participar, questionar, produzir, decidir, transformar, sendo parte integrante da dinâmica social em todas as suas estâncias.

Nesta engrenagem, e com a diversidade das Tecnologias Digitais em Rede (TDR), dentre elas o Skype, que os professores ousaram enfrentar a distância espacial, que faz parte do universo do Ensino Médio com Intermediação Tecnológica (EMITec), e apropriar-se dessa ferramenta para dialogar e promover uma aula interativa com outros profissionais que se encontravam distantes, espacialmente de nosso ambiente, mas perto virtualmente para realização de uma aula interdisciplinar na área de Linguagens, Códigos e suas Tecnologias junto aos alunos da $3^{\text {a }}$ série do ensino médio.

\section{CONHECENDO UM POUCO DO UNIVERSO DO EMITEC}

O Ensino Médio com Intermediação Tecnológica (EMITec) tem seu centro localizado no município de Salvador, no Estado da Bahia, funcionando desde 2011. Em 2017 atendeu a 21.000 (vinte e um) mil estudantes situados em localidades de difícil acesso da zona 
rural, em 403 localidades, de 149 municípios, totalizando 1221 turmas, distribuídas nos turnos matutino, vespertino e noturno. Para que as teleaula ocorram o EMITec faz uso de uma solução tecnológica viabilizada por uso de uma plataforma de telecomunicações via satélite com o software IP.TV (Internet Protocol Television), que inclui recursos como videoconferência - Figura 1, permitindo o desenvolvimento de metodologias ativas, interativas e colaborativas, aspectos que facilitam o processo de ensino e aprendizagem.

Figura 1. Infraestrutura tecnológica do EMITec

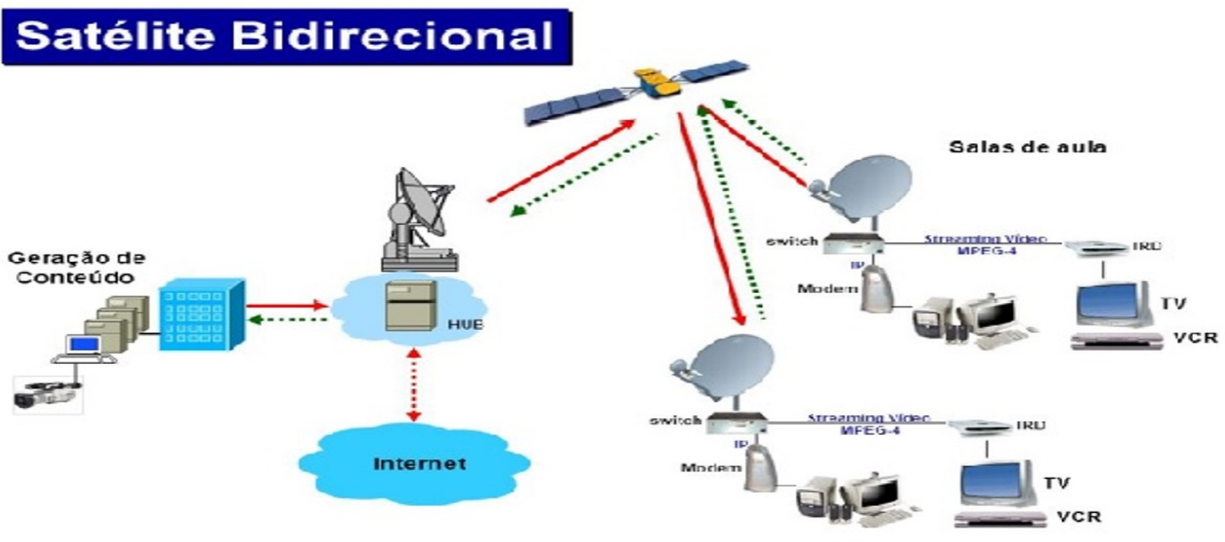

Fonte: EMITEC/SEC/BA, 2018.

Pedagogicamente, a proposição de trabalhos que sejam desenvolvidos a partir da interdisciplinaridade é um norte do Projeto Político Pedagógico do EMITec. Em comum acordo com a Base Nacional Comum para o Ensino Médio, o currículo do programa é organizado por áreas do conhecimento, estabelecendo um diálogo entre si e com os eixos norteadores, de forma que contribuam para a ampliação e compreensão de conceitos e questões fundamentais para a elevação da escolarização e das práticas sociais, numa perspectiva de interdisciplinaridade e contextualização (BAHIA, 2011).

\section{OBJETIVOS}

\section{GERAL:}

- Promover uma reflexão sobre o potencial e o uso pedagógico de artefatos tecnológicos, mais especificamente o Skype, em aulas interdisciplinares no EMITec.

\section{ESPECIFICOS:}


- Apresentar o uso do artefato tecnológico Skype no processo educacional;

- Possibilitar a construção de conhecimento significativo, de forma interdisciplinar e colaborativa através do uso do Skype na área de Linguagens, Códigos e suas Tecnologias.

\section{REFERENCIAL TEÓRICO}

Com o avanço tecnológico, no século XXI, a EaD ganhou maior condição de qualidade graças às inúmeras possibilidades de instrumentos, estratégias de aprendizagem e facilidade de acesso aos mecanismos que fazem com que o ensino e aprendizagem seja levado aos locais mais distantes.

Os recursos pedagógicos explorados com o uso da Internet podem ser utilizados de forma articulada aos conteúdos abordados em sala de aula. Quando o professor conhece as ferramentas e sabe utilizá-las consegue orientar a aprendizagem, aliando a intencionalidade pedagógica ao interesse dos estudantes. Usamos tecnologia porque, com recursos lúdicos e contemporâneos, podemos educar crianças e jovens para viver com responsabilidade, criatividade, espírito crítico, autonomia e liberdade em um mundo tecnologicamente desenvolvido (NEVES, 2005 apud SANTIAGO et al, 2016, p. 7-8).

Ainda nesse contexto, vale destacar a utilização do Skype, ferramenta de comunicação instantânea, voz e texto, um artefato ou recurso tecnológico que vem adquirindo uma importância relevante no processo de ensino e aprendizagem, e que inclusive pode integrar formatos midiáticos híbridos, ou seja, não só textos, mas também sons, imagens, vídeos, promovendo, inclusive, a interdisciplinaridade e difundindo conhecimentos.

As práticas de trabalhos interdisciplinares têm a finalidade de integrar educadores em um trabalho conjunto entre disciplinas de modo a superar a fragmentação dos conteúdos, é o objeto a partir de múltiplos pontos de vista disciplinares. Nicolescu (1999) considera que a interdisciplinaridade é a transferência de métodos de uma disciplina para outra, contribuindo par a construção de conhecimentos e compreensão dos fenômenos.

A evolução que vem ocorrendo com o uso dos artefatos tecnológicos que vem sendo vivenciada na educação, determina entre outros aspectos, que "[...] a educação se realiza em outros lugares além da escola [...].", podendo-se dizer que "[...] não existem fronteiras quando se utiliza a Internet para a aprendizagem das pessoas [...]." (GOMEZ, 2004, p. 22). 


\section{PROCEDIMENTOS METODOLÓGICOS}

$\mathrm{Na}$ ação metodológica aqui adotada para a utilização do Skype durante a aula interdisciplinar, buscou-se atingir um dos objetivos propostos pelo programa EMITec, discutir interdisciplinarmente o tema transversal da unidade letiva "Empreendedorismo e Economia Solidária" na vertente da área de Linguagens, Códigos e suas Tecnologias. A prática pedagógica, adotada, teve como norte a busca de artefatos tecnológicos nos quais o processo de ensino e aprendizagem ocorressem com o uso de metodologias ativas, de forma interativa, fazendo com que houvesse o confronto e discussão de ideias, além do feedback dado pelos participantes em tempo real, levando à construção de novos conhecimentos colaborativamente.

Para auxiliar na consolidação da discussão da temática, buscou-se utilizar o artefato tecnológico, o Skype, para que um convidado externo pudesse trazer sua colaboração acerca do tema transversal, proporcionando a discussão em tempo real, com o uso de outros artefatos tecnológicos que já fazem parte da metodologia desenvolvida pelo EMITec que possibilitam a veiculação de áudio, imagens, vídeos, textos, envolvendo todas os alunos da $3^{\underline{a}}$ série do Ensino Médio e, assim, atendendo o principal objetivo da discussão, a agregação de informações, construção de conhecimento e a maior possibilidade de interação entre todos os envolvidos.

Para a elaboração desse relato de experiência, metodologicamente, fez uso da pesquisa bibliográfica que deu o aporte teórico do trabalho, e da pesquisa de campo junto ao Programa EMITec.

\section{APRESENTAÇÃO E DISCUSSÃO DOS RESULTADOS}

A realização da atividade interdisciplinar na área de Linguagens, Códigos e suas Tecnologias consistiu na discussão do tema transversal de uma unidade letiva "Empreendedorismo e Economia Solidária". A aula foi realizada pelas docentes de Arte, e de Língua Portuguesa, tendo como convidado externo Uirã Oliveira, graduado em Administração de Empresas e Mestre em Planejamento Territorial pela Universidade Estadual de Feira de Santana, UEFS/BA, localizado no município de Valente/BA, conforme Figura 2 e que é especialista em economia solidária no estado da Bahia.

Figura 2. Momento da aula interdisciplinar com o uso do Skype 


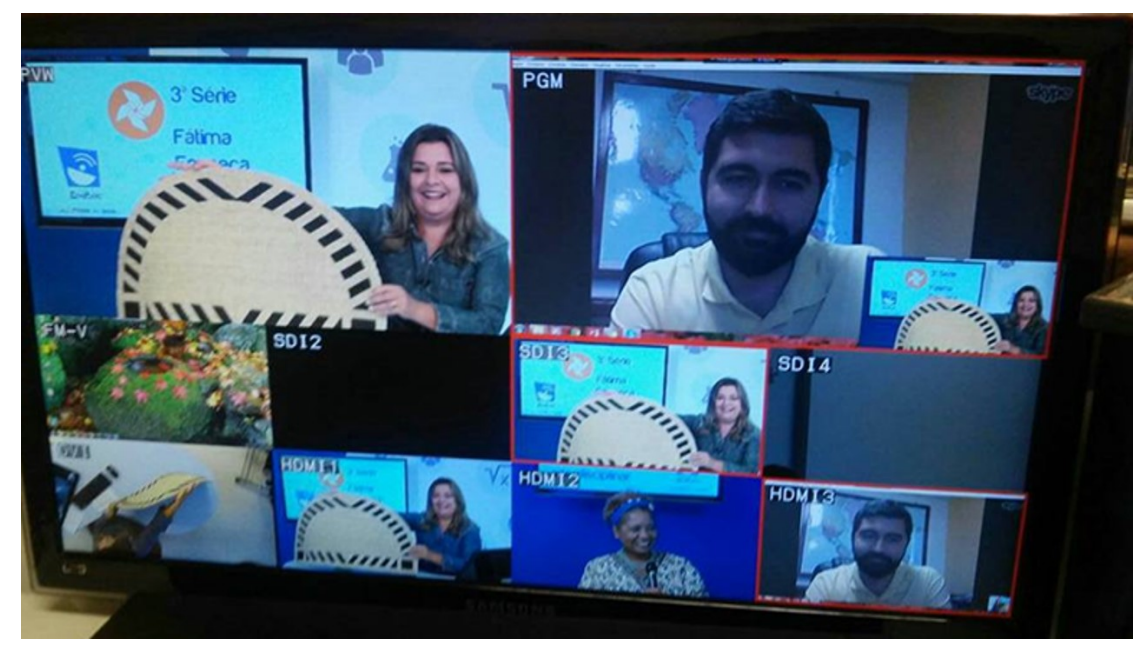

Fonte: EMITEC/SEC/BA, 2017.

Com o objetivo de discutir o tema transversal "Empreendedorismo e Economia Solidária", fazendo uso do artefato tecnológico, especificamente o Skype, os professores no EMITec puderam dialogar com o convidado externo, diretamente da cidade de Valente/BA e, ao mesmo tempo, tele-transmitir em tempo real, através do sistema de IP.TV, para as salas de aulas da 3aㅗ série do Ensino Médio nas diversas localidades da zona rural do estado da Bahia.

Os alunos, por sua vez, puderam interagir via chat, dialogando com os envolvidos, e consequentemente, produzindo conhecimentos, de forma colaborativa e interativa. Para Sales (2013), se os sujeitos interagem e produzem conhecimento de forma cada vez mais dialógica e autônoma, estes são processos de difusão social do conhecimento, que articulam em redes, diversas e inter-relacionadas, o aprendizado formal e informal.

Para Moran (2000 apud MULLER, 2013) as tecnologias não substituem os docentes e suas práticas pedagógicas, mas ampliam os bons professores, lembrando que a cada inovação tecnológica utilizada, uma adequação estratégica pedagógica deve ser cuidadosamente planejada.

\section{CONSIDERAÇÕES FINAIS}

O advento da Internet, vem oferecendo uma série de ferramentas e possibilidades de que podem ser utilizadas nas diferentes modalidades de ensino seja a distância ou presencial. Assim, os meios ou artefatos tecnológicos são ferramentas que possibilitam a intermediação entre professores e alunos em diferentes lugares do planeta, com desafios e inovações e de grande relevância social, como foi o caso aqui apresentado, com o uso do Skype em uma aula interdisciplinar. 
Assim, as possibilidades oferecidas pelos artefatos digitais para o processo de ensino e aprendizagem são infinitas. É preciso que se tenha coragem de ousar e torná-los uma prática efetiva dentro dos ambientes educacionais. O Skype é uma ferramenta digital interativa, um espaço de criação, troca e construção de conhecimentos, informações e comunicação, além de encurtar distâncias.

O trabalho interdisciplinar realizado pelos professores de Linguagens, mas especificamente pelos professores de Arte e Língua Portuguesa do EMITec, possibilitou a convergência de conhecimento entre as disciplinas sobre o tema transversal Empreendedorismo e Economia Solidária entre as disciplinas. Foi uma experiência exitosa, que teve como resultado principal a aprendizagem colaborativa como um processo ativo, interativo.

Desta forma, o uso dos artefatos digitais visa compartilhar conhecimento, interagir, estabelecer novas conexões, construir novos espaços de saberes e dar novo significado a novas formas de aprendizagem. Mattar (2013) ressalta que apesar da distância física, é possível administrar pedagogicamente os educandos para que aconteça, através da interatividade, do diálogo, da participação e da autonomia a concretização real da aprendizagem.

\section{REFERÊNCIAS}

BAHIA, Projeto Político Pedagógico do Ensino Médio com Intermediação Tecnológica -EMITec, 2011.

BONILLA, Maria Helena Silveira. Inclusão digital nas escolas. Dísponível em: http://ww w.universidadenova.ufba.br/twiki/pub/GEC/RepositorioProducoes/artigo_bonilla_mesa_ inclusao_digital.pdf. Acesso: 05/05/2018.

CASTELLS, Manoel. Sociedade em rede. Tradução de Roneide Venâncio Majer. São Paulo: Paz e Terra, 1999.

GOMEZ, Margarita Victoria. Cibercultura, formação e atuação docente em rede: guia para professores. Brasília: Liberlivro Editora Ltda, 2010.

MORAN, José Manuel. Gestão inovadora da escola com tecnologias. IN: VIEIRA, A. (Org). Gestão educacional e tecnologia. São Paulo: Avercamp, 2003. p. 151-164. 
Pedagógica, Papirus, 21ํ , 2013 .Ed. São Paulo Pg. 21-24

MORAN, José Manuel; MASETTO, Marcos; etall. Novas Tecnologias e Mediação Pedagógica. São Paulo: Papirus, 2000.

NICOLESCU, Basarab. O Manifesto da Transdisciplinaridade. Tradução de Lúcia Pereira de Souza. São Paulo: TROIM,1999.

RAMAL, Andrea Cecilia. Educação na cibercultura: hipertextualidade, leitura, escrita e aprendizagem. Porto Alegre: ARTMED, 2002.

SALES, Kathia Marise Borges. Cognição em ambientes com mediação telemática: uma proposta metodológica para análise cognitiva e da difusão social do conhecimento. Salvador, 2013

SANTIAGO, Larisse Barreira de Macêdo et al. Uso dos artefatos tecnológicos virtuais e digitais na escola. ARTEFACTUM - Revista de Estudos em Linguagem e Tecnologia, ano VIII, n 02, 2016. 